\title{
Anthropological interpretation of eugenics and Transition--The Case analysis of Daur Marriage and Family Common Law
}

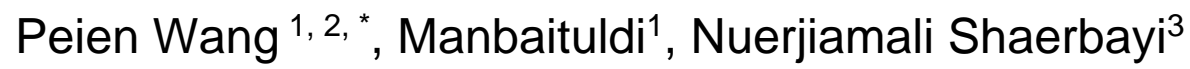 \\ ${ }^{1}$ Xinjiang Normal University Institute of Ethnology and Sociology, Urumqi, Xinjiang, 830063, China; \\ ${ }^{2}$ Party School of the Communist Party of Teaching Area, Teaching, Xinjiang, 834700, China; \\ ${ }^{3}$ Key Laboratory of Oasis Ecology of Ministry of Education, College of Resources and Environmental \\ Science, Xinjiang University, Urumqi 830046, China. \\ *wpe313@sina.com
}

Keywords: Common law, ethnology, eugenics, medical anthropology.

\begin{abstract}
In view of anthropology horizon, Dour in Asher Township still utilizes the minority common law in the legal environment with certain limitation, especially the marriage and family common law. In the process of realizing harmonious society of modernization legal system and legal pluralism, it is necessary to examine the relationship between the common law and the national law, explore the transition of common law in the context of national law, and seek their coupling to realize the benign complementary of common law and national law. Only in this way can we further realize the irreplaceability of common law in constructing diversified legal culture and explore new path more in line with the construction of legal system in minority regions.
\end{abstract}

\section{Introduction}

About 250 years ago, Dour migrated from Heilongjiang to Xinjiang under orders and lived in Asher Township, Teaching at present. They strictly abide by and inherit the customary law of the nation, especially the marriage and family common law. Affected by many factors, the marriage and family common law of the dour people has changed to a certain extent in terms of content, form and function. In order to understand the current situation, we carried out multiple special field investigations in the Asher Township. Taking Harare exogamy system, divorce common law and ultimo geniture as the research objects, this paper describes the current situation of dour marriage and family common law and analyzes the reason for its transition based on the investigation data.

\section{Introduction of Asher Township}

In the 28th year of Emperor Qianlong in Qing Dynasty (1763 A.D.), in order to consolidate the rule over the Northern Tianshan Road and avoid the drawbacks of alternate station, Qing Government decided to command the armymen of Daur and Evenki and their wives and children to defend Ili. In autumn in the same year, more than 500 armymen of the two minorities immigrated to Ili together with their wives and children, quartering at Khorgos River. Hereafter, 130 officers were transferred by Ili General and dispatched to garrison Tarbahar appeasement (belong to Tacheng). After the Revolution of 1911, the system of Eight Banners was abolished, and the Daur people of Suijing City immigrated to Asher Township 18 kilometers away the current Tacheng in the northeast and cultivated the virgin land. The full name of Asher Township is Asher Dour national town. It has a total area of 402 square kilometers, including about 10000 population and 19 nations living together. According to the statistical data in 2011, there are a total 5417 people, accounting for 51.96\%, 2187 Daur people, accounting for 20.69\%, 1783 Kazak people accounting for 16.5\%, 5417 Hui people accounting for $7.27 \%$, and 377 people from other 15 nations accounting for $3.57 \%$. Before the reform and opening up, "the Daur people lived together with the Kazak, and their economy and culture are closely relevant. Therefore, most Daur people here understand Kazakh language. Some children even only understand Kazakh language, while do not understand the language of their own nation.” 
"Before the Revolution of 1911, the Daur people spoke both the language of Manchus and Chinese. After the founding of new China, children of Daur went to schools that offer courses in Chinese." The common language creates more possibilities to ethnic intermarriage and deepens the interaction with the Han nationality.

\section{Transition of Marriage and Family Common Law}

\subsection{Harare Mound Organization-Defender of Common Law.}

Daur has its national language, but there is no corresponding character. Therefore, the written common law is scarce. The formulation and implementation of common law in Daur depend on Harrar Mokun which is a consanguinity clan organization. Clan is not only a social organization of Daur, but also a social management organization. Correspondingly, the hereditary common law maintains the social order of Daur. It includes a wide range of contents, such as public property management, sacrifice and genealogy repair, inheritance law, and marriage rule. In the era in which clan organization is the only social organization, common law is the major legal norm of Daur. The marriage common law of Daur includes marriage, divorce, adoption and inheritance, etc. The author reviewed the relevant literature, finding that marriage and family common law of Daur is composed of three parts: Harrar exogamy system, divorce common law and ultimogeniture. The contents of the three parts are illustrated by combining with the field investigation in Asher Township.

\subsection{Harare Exogamy System-Members from the Same Harare Cannot Intermarry.}

Harrar exogamy system stipulates that members of the same Harrar cannot intermarry because of the Haur people's belief that members of the same Harrar "belong to the descendants of the same ancestor and have the same consanguinity." The Dour people think that the intelligence of their descendants will be affected if they intermarry, which is extremely detrimental to the development of the family. Therefore, members from the same Harrar are forbidden to intermarry. "In the late Qing Dynasty and the early Republic of China, assistant commandant Guobule Ga got married with a woman from the same Harrar and was excluded from the genealogy by Mokuun organization.” Even after the promulgation of the Marriage Law, Harrar exogamy system is continuously used. "The people named Mordent bang was criticized by the clasmen because he married a woman from the same Haur, although they were distant relatives, and their marriage did not violate the provisions of the Marriage Law.” This indicates that Harare exogamy system is still regarded as the common law taboo that cannot be violated after the promulgation of the Marriage Law.

The old man called Jiazi recalled that small Daur population lived in Tachang prefecture, and it was agreed that the taboo of the intermarriage between the members of the same Harrar was changed into members beyond five generations of the same Harrar can intermarry. However, there was no such case in the investigation process. Moreover, the author also examined the Daur people's understanding of Harrar exogamy system as a common law. The local Daur people believed that the intelligence of the descendants will be affected if members of the same Harrar intermarry, which is a taboo for both family and nation. Harrar exogamy system is accepted and observed as a common law followed by hundreds of years. Meantime, the increasing toleration for the ethnical intermarriage also provides living space for Harrar exogamy system. Ethnical intermarriage can spread the intermarriage wide and support Harrar exogamy system more extensively.

\subsection{Divorce Common Law-Mound Grant Letter as the Proof.}

Such proverbs are spread in Daur, "the place where the divorce letter is written will be barren", "spare whip will not be prepared for a good horse, and a courageous woman will not remarry". This indicates that the Daur are extremely opposed to divorce, and they believe that divorce is inglorious and ominous. Therefore, they will not divorce easily.” Divorce conditions are extremely harsh. Specifically, they will consider divorce only when they have proper reasons, for example, the man does not attend to his proper duties, the women is abused, or the couple is bad terms with each other. Mokun of the two parties will be invited for conciliation, and only with the consent of Mokun of both parties can they divorce. Afterwards, the divorce letter will be written in the open and torn as the proof of divorce. After divorce, what the woman can take away is only her dowry, and children are 
raised by the man. The remarriage of both parties will not be limited. The author interviewed the staffs of Office of Justice in Asher Township, and checked the mediation documents of marriage and family of Daur. There is only one from 2011 to May 2014. Finally, man and his wife reached the agreement on property and child support according to the mediation document and transacted divorce formality in Tachang Civil Affairs Bureau. The judicial official states that the two sides expressed their approval of the mediation of in terms of emotion and property disputes. Both parties recognized the legal force of mediation document. If one party fails to comply with the agreement, the other party may appeal to the court by taking the mediation document as evidence. According to China's Marriage Law, two sides can adopt divorce by agreement and divorce by litigation. Accordingly, we can see that the divorce form stipulated in the marriage and family common law of Daur does not comply with the relevant provisions of the national law. From the perspective of legal effect, the authority of the divorce common law cannot be protected by national law. In the interview, the leader of Harare Mokun Organization named Damo said that the main work of the leader of Harrar Mokun Organization is to preside over the internal wedding and funerals and discuss the matters concerned in sacrifices. It no longer involves the conciliation of divorce. This indicates that the function of the leader of Harrar Mokun Organization is gradually weakened. The leader of Harare Mokun Organization also recognizes the authority of the national law, and argues that the relevant administrative and judicial processes are effective ways to solve the disputes in marriage and family. Although the leader of Harrar Mokun Organization has certain social function, the authority has been weakened.

\subsection{Ultimo Geniture- the Youngest Son Will Inherit the Property When There Are Multiple Children in A Family.}

The order of succession stipulated by traditional common law is: In the case that here are multiple children in a family, the primary inheritor is the youngest son.If there is no youngest son, the inheritor is the son-in-law who lives in the home of his wife's parents. When there is neither youngest son nor son-in-law, the nephew will be considered as the inheritor. Daur common law stipulates that daughters have no right of succession, unless there is no son in the family. Otherwise, family members and organizations have the right to interfere. According to the investigation and statistics of families with multiple children, the author analyzed the transition of ultimogeniture.

The Daur people generally understand the order of succession stipulated in the inheritance law. However, most old parents still live with and are supported by the youngest son according to the common law. Therefore, their property will be inherited by the youngest son after death. Most Daur people follow the common law. In the interview, the Daur people said that their older brothers leave their home after marriage, while the youngest children still live with and support their parents after marriage. Other children could go and see their parents. Therefore, it is generally believed that ultimogeniture is deserved, which is a compensation for the youngest children for filial obedience. It can be seen that the key factor of ultimogeniture is support. Based on this situation, the author further summarized the support situations of the 47 families.

It can be seen that most old parents of Daur live with the youngest children. The Daur people believe that it is deserved to support the elderly. The elderly live together with the youngest children. On the one hand, their daily life is taken care of by the youngest children. On the other hand, they can relieve the loneliness of the elderly. What the common law expresses is the family idea that the elderly could be looked after properly. All Daur people grow up in such culture, and form the corresponding idea. Ultimogeniture is the compensation for their duty of support the elderly. Moreover, parents will prepare family property for their sons when they get married, or dowry for their daughters. This is equivalent to that other children inherit part of the parents' property. Therefore, in view of the inheritance, although the stipulation in inheritance law is generally aware, they think that ultimogeniture is more in line with their rules. It seems that inheritance law is contradictory to the content of inheritance common law in Daur, they have the common principle. This is because the national law also complies with the idea that filial piety is the foundation of all virtues and aims to realize that target that the elderly will be looked after properly. 


\section{Inheritance, Assignment, and Coupling}

The Daur people live in Asher Township as the minority group, and their culture is unconsciously influenced by the external group. Their marriage and family common law is likely to transit because of the influence of ethnic intermarriage and daily communication. Both change and inheritance exist in the three aspects of Harrar exogamy system, divorce common law and ultimogeniture. The idea and behavior of the Daur people on marriage and family has transited unconsciously, while the culture function of cultivating descendants and inheriting virtue is still reserved. In the transition of Harrar exogamy system, people adhere to the marriage and family idea conveyed in the common law. Forbidding marriage for close relatives" and "enlargement of intermarriage circle" aim to enhance the quality of the national population and cultivate excellent descendants. This does not conflict with the concept behind the Marriage Law. Affected the idea of common law, the Daur people think divorce should be deliberated because it is inglorious. Meantime, they can also accept divorce for legitimate reasons, and do not ignore individual happiness. At present, the national legal system has been increasingly improved, and common law has largely transferred power to the national law. In the transition of common law in the three aspects, it can be seen that common law as national culture maintains people's feelings that they cannot give up and conveys the values of the nation. The coercive force of common law is gradually weakened, and it cannot regulate people's life as a kind of institutional power. However, this doesn't mean that it has been out of people's lives. The common law containing excellent national culture is still observed by people. As for the field that common law cannot involve, the right should be transferred to the national law. The coupling zone between common law and national law exists between inheritance and assignment.The daur nationality has a relatively perfect marriage and breeding system. As a family-oriented society, the important purpose of childbirth is to reproduce the clan, and eugenics has become the most important pursuit in the local traditional marriage and family culture. In the past, when genetics was not developed, people used common law to regulate marriage and family behavior, and its ultimate goal was to ensure eugenics. According to China eugenicists Pan Guangdan eugenics is a combination of natural environment and social environment of cultural phenomenon, if the rings of marriage system is to ensure that avoid incest may bring offspring health concerns, of the divorce law to a certain extent, also for future generations a complete family social structure as much as possible.He advocates a kind of compromise system, which would hold family roots, and to its branches, the organization of the family old and eclectic, postadolescent and young generation, three of the daur their inheritance system prompted this three runs in the family structure.

\section{References}

[1]. Local Chronicles Compiling Commission of Teaching City. 1995. Chronicles of Teaching City. Urumqi: Xinjiang People's Publishing House.

[2]. Goo Bailing, Goo Balden.2013. The Dour of Xinjiang, Teaching City. Urumqi: Xinjiang People's Publishing House.

[3]. Si Qing.1936. Outside Record of Heilongjiang (volume 6).Shanghai: Business Printing Embassy.

[4]. Goo Keying. 1998. The Dour Data Set: Henry of Dour, Henry. Beijing: National Publishing House.

[5]. An Editorial Board of the Daria Data Set. 2003. A fourth Episode of The Daria Collection. Beijing: National Press.

[6]. Battuta. 1991. The Custom of the Dour. Beijing: National College Press.

[7]. Yong Baoji, Ma Dashing, Nia Pinkham. 1990. Collection of Historical Documents of the Qing Dynasty in Xinjiang: the President's Project. Beijing: Literature Center of the National Library. 
[8]. Yuan Zhuang. 1990. The Cultural Connotation of the Dour Marriage Law. The Social Economy of Xinjiang (1): 74-75.

[9]. Zhang Shenyang, Wang Xiaoping. 2005. Rational Thinking on the Modernization of Chinese Legal System. Front (1): 121-124.

[10]. How Yuan Feng. 2002. National History Research: The Solon and Dour in Xinjiang. Beijing: National Publishing House.

[11]. Li Jimmie, GAO Ying. 2002. The Soren Camp in the Qing Dynasty. Journal of the Xinjiang Vocational College (4): 105-107.

[12]. Cain Xingjian. 1996. The Evolution and Transformation of the Chinese Legal System: Go to the Road of the Law. China Law (5): 3-10.

[13]. Jiang Lichen. 1995. Characteristics of the Modernization of Chinese Legal System. Chinese and Foreign Law (4): 11-13. 